\title{
GENC Entity 2
}

National Cancer Institute

\section{Source}

National Cancer Institute. GENC Entity 2. NCI Thesaurus. Code C123748.

A geopolitical entity designated by the Geopolitical Entities, Names, anc Codes Standard (GENC). 